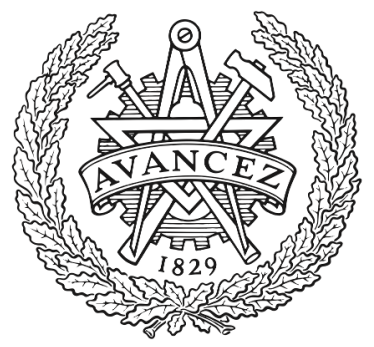

CHALMERS

UNIVERSITY OF TECHNOLOGY

\title{
SU8 ridge-gap waveguide resonator
}

Downloaded from: https://research.chalmers.se, 2023-04-26 07:09 UTC

Citation for the original published paper (version of record):

Rahiminejad, S., Pucci, E., Haasl, S. et al (2014). SU8 ridge-gap waveguide resonator. International Journal of Microwave and Wireless Technologies, 6(5): 459-465. http://dx.doi.org/10.1017/s1759078714000609

N.B. When citing this work, cite the original published paper. 


\section{SU8 Ridge Gap Waveguide Resonator}

Sofia Rahiminejad ${ }^{1}$, Elena Pucci $^{2}$, Sjoerd Haasl $^{3}$, Peter Enoksson ${ }^{1}$

${ }^{1}$ Department of Microtechnology and Nanoscience, Chalmers University of Technology, Kemivagen 9, 41296 Gothenburg, Sweden

${ }^{2}$ Department of Signals and Systems, Chalmers University of Technology, Hrsalsvgen 11, 41296 Gothenburg, Sweden

${ }^{3}$ School of Technology and Health, Royal Institute of Technology, 14152 Stockholm, Sweden

In this paper we present the first ridge gap waveguide resonator made with a polymer base. It is designed for the frequency range $220-325 \mathrm{GHz}$, and is fabricated solely using a Au coated two-layer SU8-based process. The design is based on previous work done with Si. The new process has advantages such as fewer process steps and cheaper process steps. The SU8 ridge gap waveguide resonator is made in order to obtain attenuation characteristics via the measured Q-factor of the resonator. The ridge gap waveguide resonator has the same dimensions as the previous one fabricated in Si, and the same thickness of the Au coating. The SU8-based resonator shows an attenuation loss of $0.041 \mathrm{~dB} / \mathrm{mm}$ at $282.2 \mathrm{GHz}$ compared to the Si-based resonator with an attenuation loss of $0.043 \mathrm{~dB} / \mathrm{mm}$ at $283.5 \mathrm{GHz}$. This makes the SU8 process a more cost-effective alternative to the Si process

Corresponding author: S. Rahiminejad; email: rahimine@chalmers.se; phone: +46 31772 1874

\section{INTRODUCTION}

SU8 is an epoxy-based negative photoresist, which is often used for patterning or as sacrificial layers in MEMS processing. Recently SU8 has been used as device material also for RF-MEMS applications. WR-03 band rectangular waveguides fabricated by CNC milling, KMPR-based LIGA and with SU8 have been compared to each other by Shang et al [1]. They presented that the SU8-based rectangular waveguide insertion loss $(\sim 0.031 \mathrm{~dB} / \mathrm{mm}$ for $220-325 \mathrm{GHz})$ have a comparable level with the commercially available CNC precision-machined metal waveguides $(\sim 0.02 \mathrm{~dB} / \mathrm{mm}$ for $220-325 \mathrm{GHz}$ ). These results show that SU8 could be a promising material to fabricate high-performance high frequency waveguides.

Gap waveguide technology is based on utilizing a metamaterial, in this case a bed of nails [2], which forms an Artificial Magnetic Conductor (AMC). When a perfect electrical conductor (PEC) is placed opposite an AMC, a parallel-plate stopband is created for a certain frequency band [3]. However, if the AMC layer incorporates a guiding structure such as a ridge, groove or strip, waves can propagate along the ridges, grooves or strips without leaking away from the structure [4]. Such parallel-plate structures can be used as transmission lines as shown in Fig. 1. The wave is prohibited to propagate outside the 
ridge due to the stopband as shown in Fig. 2.

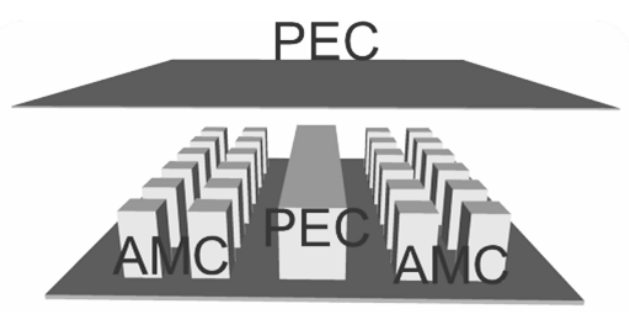

Figure 1: Illustration of a ridge gap waveguide. The ridge and the lid are PEC surfaces and the pin-surface realizes the AMC surface.

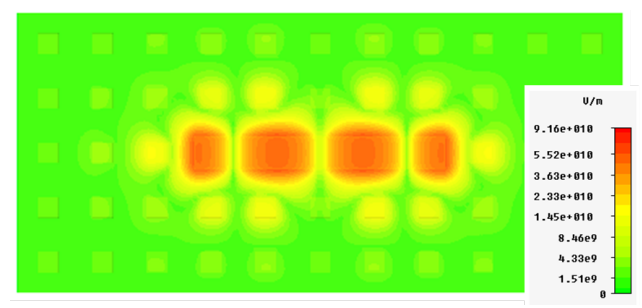

Figure 2: 2D color plot of the absolute value of E-field for the open circuit ridge gap waveguide resonator.

A gap waveguide demonstrator for $10-20 \mathrm{GHz}$ was presented in 2011 [5] and since then different gap waveguide applications have been demonstrated below $50 \mathrm{GHz}$ such as filters [6] and packaging of MMICs [15]. We have also demonstrated gap waveguides and their low loss at high frequency above $100 \mathrm{GHz}$, such as the ridge gap waveguide resonator made in Si for $220-325 G H z$ [8], the pin-flange adapter [9, 10] and the groove gap waveguide for $100 \mathrm{GHz}[11,12]$. The resonator is used as a demonstrator of the low losses of gap waveguides through measurements of the Q-factor of the resonance. The SU8 material is advantageous for manufacturing gap waveguides because of its relative low cost and simple process that lends itself well for mass production and provides high flexibility in 3D fabrication.

In this paper, we present the first polymer-based gap waveguide component, a ridge gap waveguide resonator for $220-325 \mathrm{GHz}$ made out of a two-layer Au coated SU8.

\section{BACKGROUND}

The design is based on the ridge-gap resonator for $220-325 \mathrm{GHz}$ presented in [8]. It consists of a ridge surrounded by pin structures, Fig. 3. The ridge is surrounded by two rows of pins along the long sides of the ridge and one row of pins on the connecting side (the short side). The coupling to the resonator needs to be weak, which is why there is one pin-row at the connecting sides. The pins and the ridge both have the same height of $277 \mu \mathrm{m} \pm 10 \mu \mathrm{m}$. The surrounding pins each have a top area of $165 \mu \mathrm{m} \times 165 \mu \mathrm{m}$. The gap between the pin-surface and the PEC lid needs to be smaller than $\lambda / 4$ for the 
stopband to exist. Here it has been chosen to be $167 \mu \mathrm{m}$ from the design curves presented in [3] to get a stopband between $210 \mathrm{GHz}$ and $340 \mathrm{GHz}$.

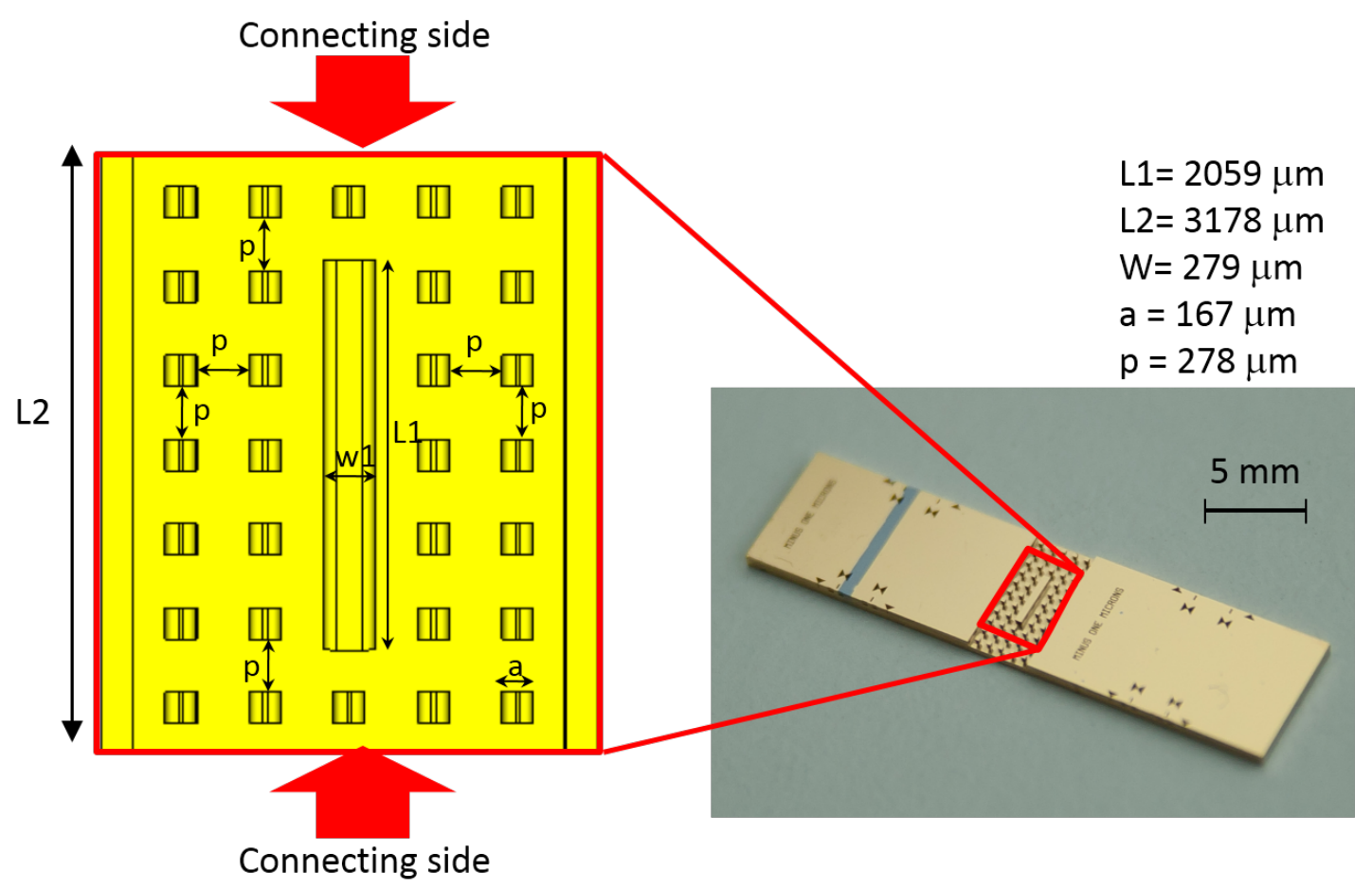

Figure 3: Top view of the ridge gap resonator, displaying the dimensions and placements of the pin and the ridge.

The lid is part of a support package also presented in [8]. Fig. 4 shows the support package with space for the ridge gap resonator and a gap of $167 \mu \mathrm{m}$ realized in the top part of this space. The package is used to support the chip when the measurement flanges are connected to it. The setup can be seen in Fig. 5, where (a) is a Network Analyzer (Agilent N5250C) connected to, (b) a millimeter-wave controller (Agilent N5260A). The millimeter-wave controller is coupled to two OML extenders constructed for $220-325 \mathrm{GHz}$ (c) where WR03 flanges (d) are connected to each side of the resonators support package (e), Fig. 4.

The previous ridge-gap resonator was completely made out of silicon and coated with gold. The full process involved several process steps such as sputtering, lithography, ICP DRIE, stripping, gold sputtering and gold electroplating and dicing. Measurements were done on the silicon ridge gap resonator and compared to simulations with the same dimensions. The measurements of the previous silicon resonator can be seen in Fig. 6, [8]. The difference with the new ridge gap resonator presented here in this paper is that instead of making it out of silicon, it is made of a two-layer SU8, coated with gold. The first layer acts as a carrier and the second layer determines the pin and ridge height. The pin width is $165 \mu \mathrm{m}$ and its intended height is $277 \mu \mathrm{m}$. 

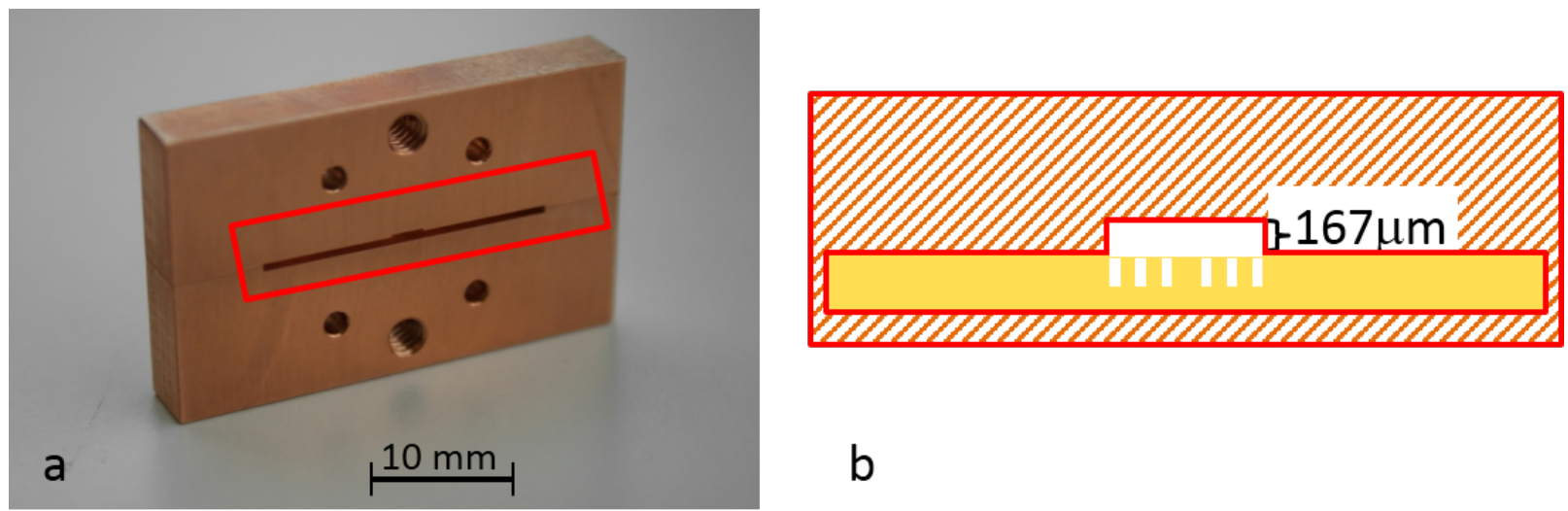

b

Figure 4: a) Picture of the support package used during measurements with the PEC lid incorporated above, b) a schematic view of the opening which fit the ridge gap waveguide resonator and have gap of $167 \mu m$ above it.

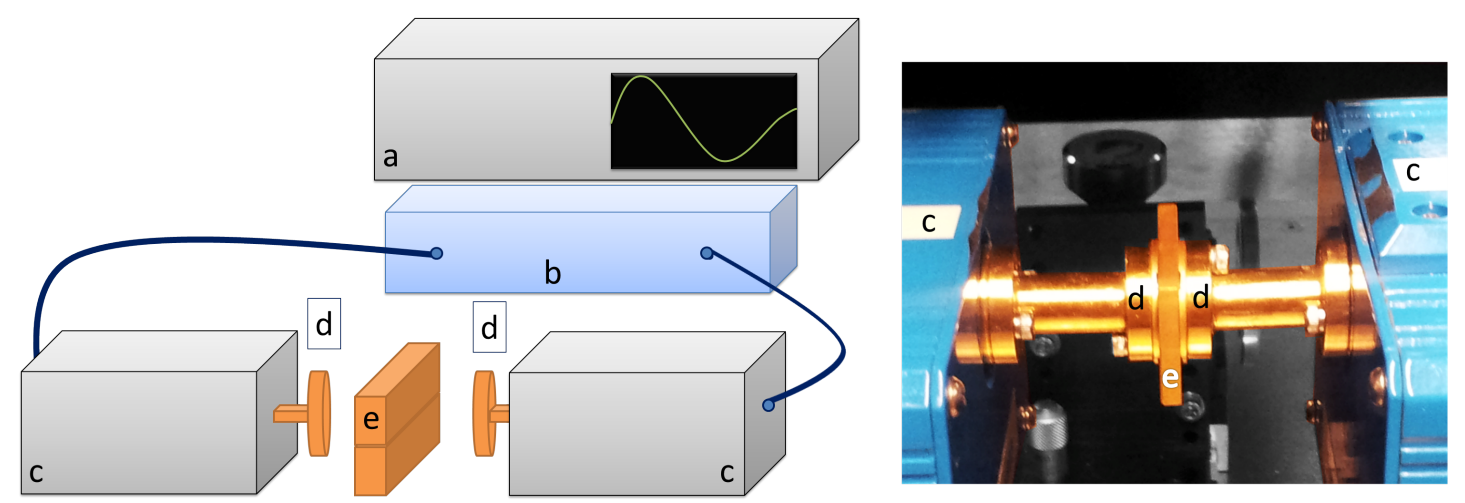

Figure 5: Measurement setup with a photo of the resonator being measured. a) The network analyzer (Agilent N5250C), b) The millimeter-wave controller (Agilent N5260A), c) OML extender, d) WR03 flange, e) Support package for the resonator (Fig. 4).

\section{FABRICATION}

The fabrication process presented here in this paper has been optimized for the ridge gap resonator structure. SU8 2150 from micro resist technology was dispensed on a 4" Si carrier wafer. First, it was spun at a low speed of $500 \mathrm{rpm}$ to distribute the SU8 over the surface, and then it was spun at $2300 \mathrm{rpm}$ to reach the desired thickness of the carrier layer, Fig. 7b. It was then soft baked in two steps, first at $65^{\circ} \mathrm{C}$ for $10 \mathrm{~min}$ followed by a bake at $95^{\circ} \mathrm{C}$ for $55 \mathrm{~min}$ on a hotplate, Fig. 7c. The two soft-bake steps are to avoid that the surface develops a crust that prevents the solvent to evaporate, and to reduce stress. It is quite common that craters or bubbles appear after the soft-bake, which was not visible before the soft-bake, Fig. 8. This can be traced back to how the SU8 was dispensed on the wafer. Several dispensing techniques are discussed at the forum memscyclopedia [13], to avoid this problem. In this work the syringe technique, the squeegee technique, pre-heating the wafer and the star-pattern have been tested. In the end a combination of pouring the SU8 directly out of the bottle and allowing it to relax for about $10 \mathrm{~min}$ 


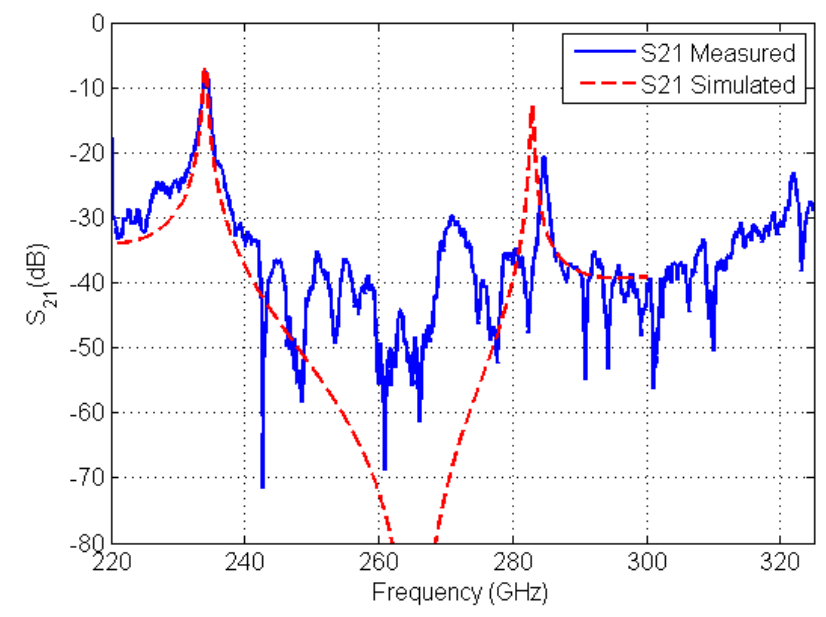

Figure 6: Measurement and simulation of the previous Si ridge gap resonator, [8].

a

b

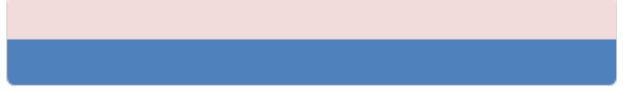

$\uparrow \uparrow \uparrow \uparrow \uparrow \uparrow \uparrow \uparrow$

$\mathrm{C}$

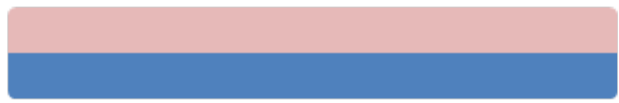

d

e

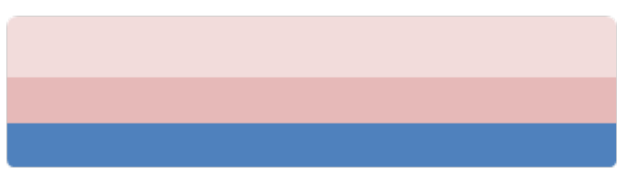

$f$

g

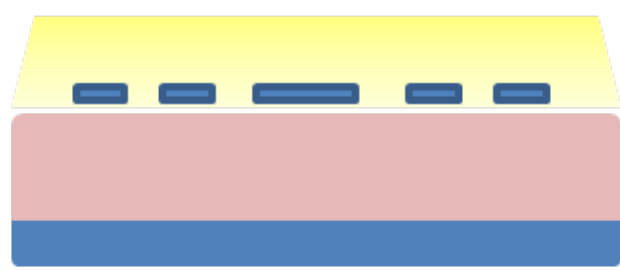

$\mathrm{h}$
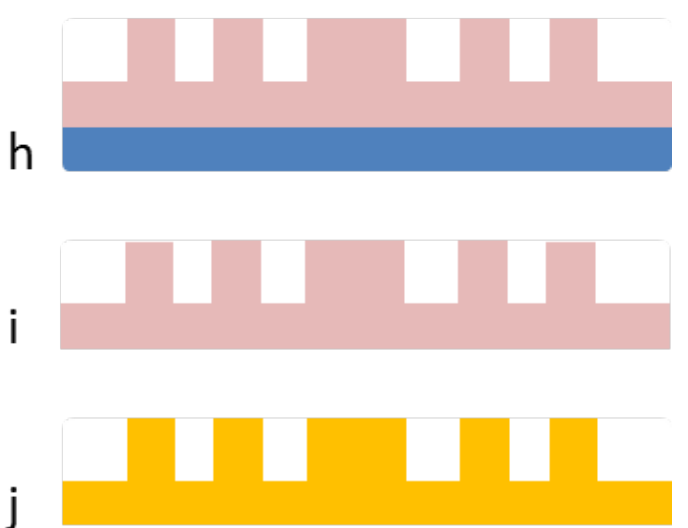

Figure 7: a) Si wafer, b) first layer of SU8 dispensed, c) soft-bake, d) flood exposure, e) second layer of SU8, f) second soft-bake, g) patterning, h) developing the SU8, i) KOH etch of the Si, j) sputtering and electroplating of Au. 
between every process step, reduces stress and the appearance of craters and bubbles.

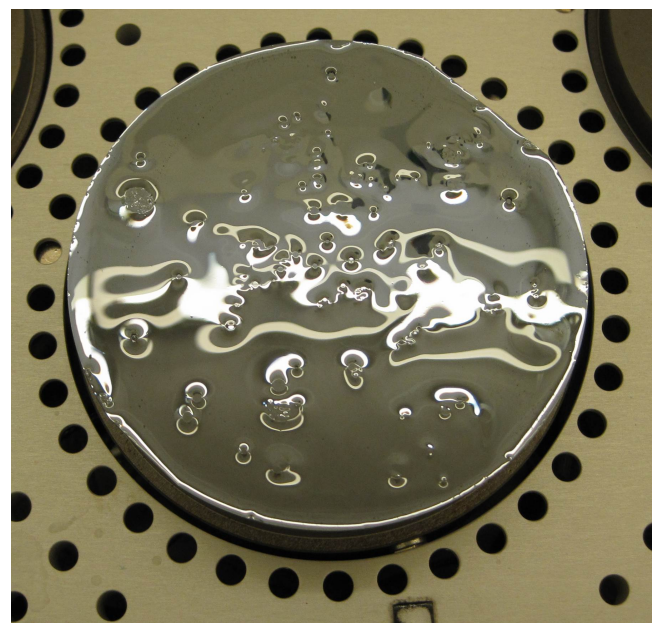

Figure 8: Craters and bubbles appearing after the first soft-bake step, due to unsuccessful dispensing of the SU8

The whole wafer was flood exposed for $62 \mathrm{sec}$ to supply enough energy for the SU8 polymers to crosslink, Fig. 7d. According to MicroChems data sheet the SU8 2150 needs about $370 \mathrm{~mJ} / \mathrm{cm}^{2}$ for crosslinking at these thicknesses. The exposure energy from the Suss MicroTec mask aligner is $6 \mathrm{~mW} / \mathrm{cm}^{2}$.

A second layer of SU8 2150 was dispensed (Fig. 7e) and distributed at $500 \mathrm{rpm}$, and then spun at $2000 \mathrm{rpm}$ to achieve the pin height of $275 \mu \mathrm{m}$. The wafer went through a second soft bake at $65^{\circ} \mathrm{C}$ for $10 \mathrm{~min}$ followed by a bake at $95^{\circ} \mathrm{C}$ for $120 \mathrm{~min}$ (Fig. $7 \mathrm{f}$ ) and was finally patterned with a negative photomask in proximity mode, Fig. 7g. Another post-exposure bake at $65^{\circ} \mathrm{C}$ for $5 \mathrm{~min}$ and at $95 \circ \mathrm{C}$ for $28 \mathrm{~min}$ was performed.

Finally, the whole wafer was developed with strong agitation for $20 \mathrm{~min}$, Fig. $7 \mathrm{~h}$. The strong agitation is needed due to that the pins will have strings of SU8 connecting them to each other otherwise. After developing for 20 min the wafer was dipped in a new developer bath and then rinsed with Isopropanol. If white marks appear during drying after the IPA rinse, the wafer needs to be developed further.

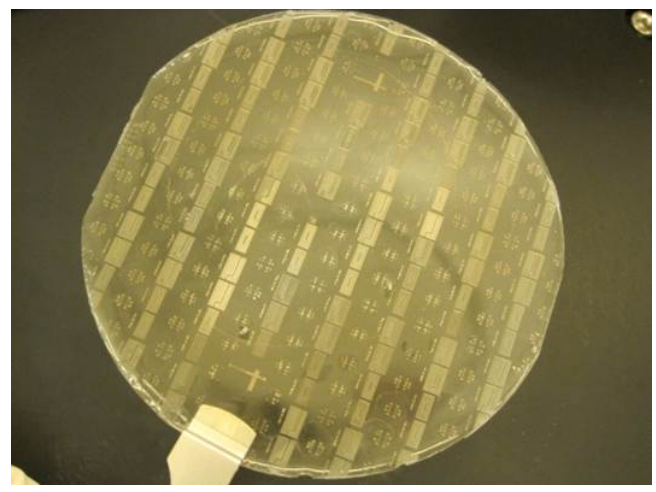

Figure 9: A complete SU8 wafer.

After patterning, the Si was removed from the SU8 by immersion in $\mathrm{KOH}$ at $80^{\circ} \mathrm{C}$. Left 
was a wafer completely made out of SU8, see Fig. 7i and Fig. 9. The SU8 wafer was then diced with a Loadpoint Microace $3+$ into resonators and sputtered with a seed layer of $\mathrm{Ti} / \mathrm{Au}(50 / 200 \mathrm{~nm})$. The SU8 resonator chip was finally electroplated with Au, Fig. 7j. To avoid skin effects a rule of thumb is that the overall thickness of the metal coating should be larger than five times the skin depth. The skin depth at $280 \mathrm{GHz}$ is $0.15 \mu \mathrm{m}$. Therefor the Au-coating was decided to be $1 \mu \mathrm{m}$ thick, the same as previously was successfully used for this device fabricated in Si [8].

The SU8 "wafer" is as easy to handle as a Si wafer of the same size. The SU8 wafer was diced, sputtered and electroplated in the same way as the Si wafer in [8].

\section{RESULTS \& DISCUSSION}

\section{A) Fabrication Results}

A two-layer SU8 ridge gap resonator was fabricated. A SEM image of the SU8 resonator and the previous Si resonator can be seen in Fig. 10. The height of the pins is $275 \mu \mathrm{m}$, which is within one percent of the desired height of $277 \mu \mathrm{m}$. The top part of the pins is slightly wider which may broaden the bandwidth because it is closer to a mushroom shape that may have larger bandwidth $[8,14]$. Fig. 11a shows a SEM image of the SU8 pin and Fig. 11b shows a SEM image of the silicon pin. The silicon pin walls have a higher slope than the SU8 walls. The slope of the Si pin could probably result in a wider bandwidth than the SU8 pin, however both structures will have a bandwidth sufficient for the WR-03 frequency band.

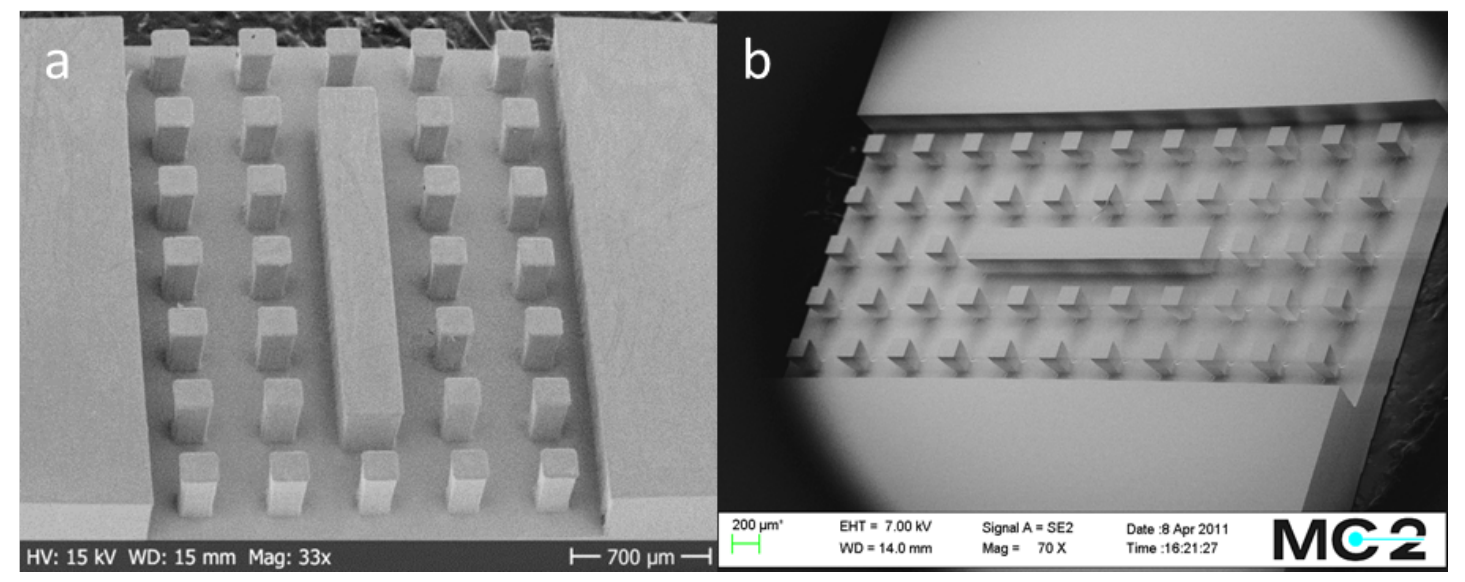

Figure 10: SEM image of a) the SU8 ridge gap resonator, with a pin height of $275 \mu m$ and b) the Si-based ridge gap resonator with a pin height of $275 \mu \mathrm{m}$.

Fig. 12 shows the ridge gap resonator made out of SU8 (Fig. 12a) next to the ridge gap resonator made out of Si (Fig. 12b). Using SU8 as only structural material allows for future low-cost fabrication processes that entirely avoid the use of Si.

The process time has been analyzed and is about the same as the Si based process in [8]. The equipment used in the SU8 based process is cheaper compared to the Si based process, where instead of using the STS ICP dry etching machine for a majority of the process time, a hotplate is used for a relatively long curing time. The material cost for 


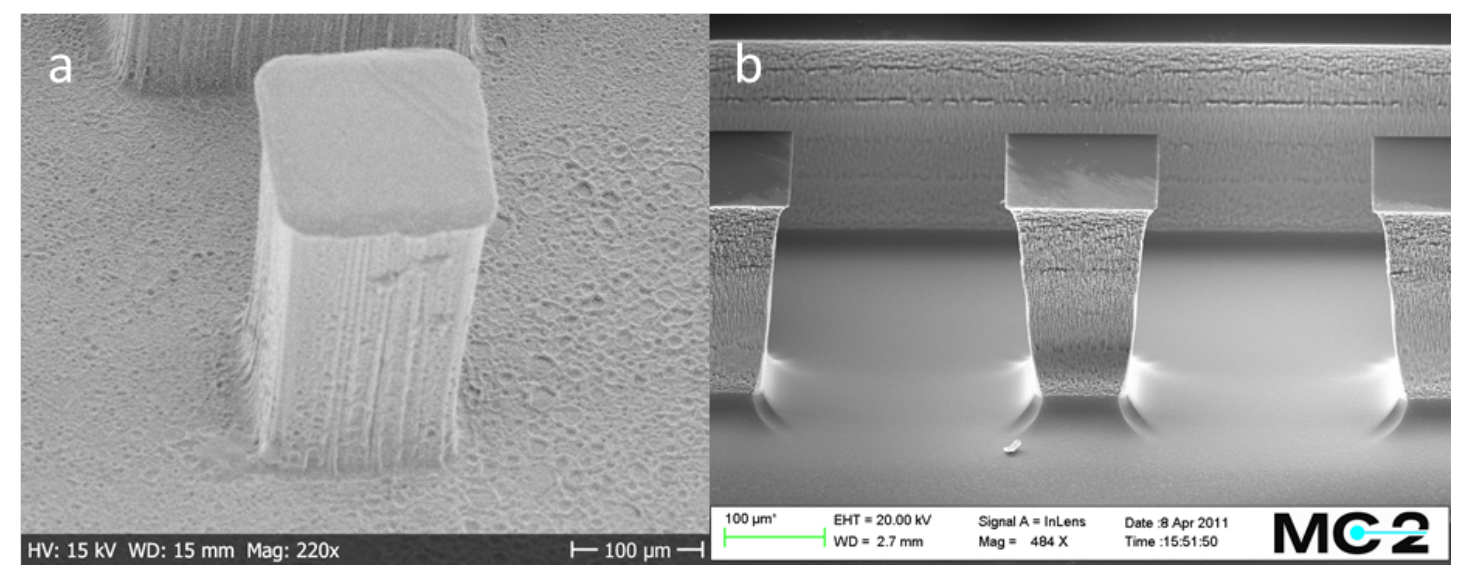

Figure 11: a) SEM image of a SU8 pin on the SU8 carrier. b) SEM image of the Si pins.

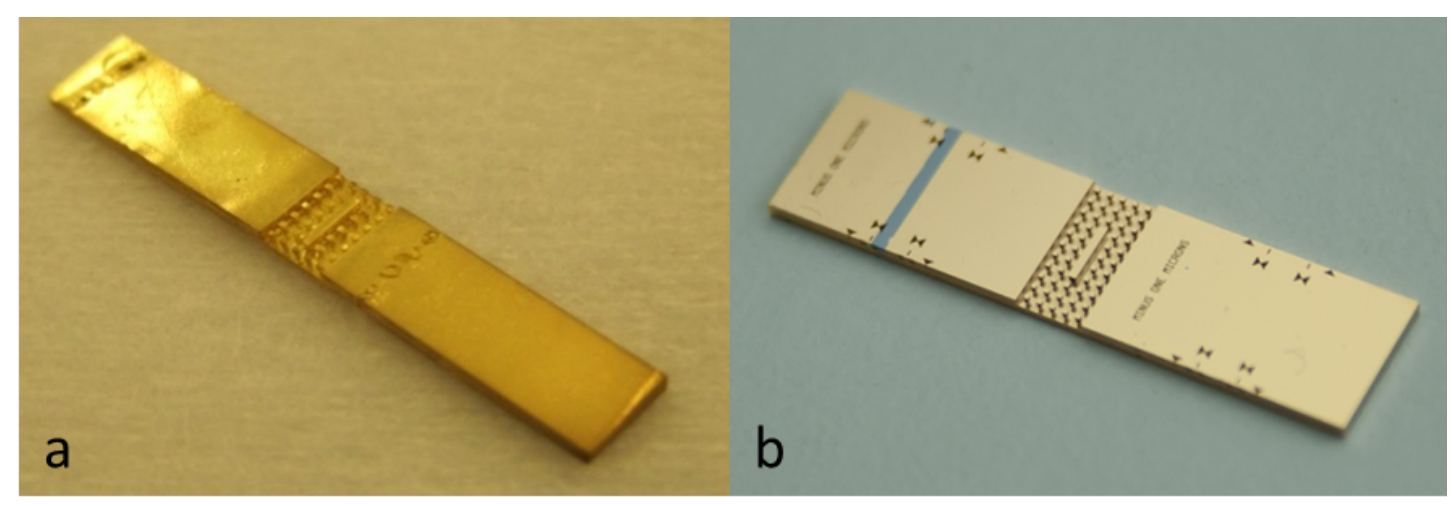

Figure 12: a) Ridge gap resonator made out of only SU8. b) Ridge gap resonator made out of silicon.

the SU8 process is also lower than for the Si process.

\section{B) Measured Results}

The measurements of the SU8-based resonator and the Si-based resonator were done for two frequency ranges, $220-260 \mathrm{GHz}$ and $270-310 \mathrm{GHz}$. These ranges were selected such as to obtain a high number of measurement points around the resonance peak. The measurements of the SU8-based ridge gap resonator and the Si-based ridge gap resonator were compared to each other and to simulations, in Fig. 13 and 14.

The resonance frequencies, the unloaded Q-values and the corresponding attenuation can be seen in Table 1 . The attenuation was calculated from the unloaded Q-values with equation $1,[15]$.

Table 1: Measured unloaded Q-values and loss $/ \mathrm{mm}$

\begin{tabular}{|l|c|c|c|c|c|c|}
\hline & \multicolumn{2}{|c|}{ Simulated } & \multicolumn{2}{c|}{$\mathrm{Si}$} & \multicolumn{2}{c|}{ SU8 } \\
\hline Frequency & $234.1 \mathrm{GHz}$ & $282.9 \mathrm{GHz}$ & $234.1 \mathrm{GHz}$ & $283.5 \mathrm{GHz}$ & $233.4 \mathrm{GHz}$ & $282.8 \mathrm{GHz}$ \\
$Q_{u}-$ value & 866 & 993 & 642 & 597 & 319 & 628 \\
Loss dB/mm & 0.025 & 0.026 & 0.033 & 0.043 & 0.067 & 0.041 \\
\hline
\end{tabular}




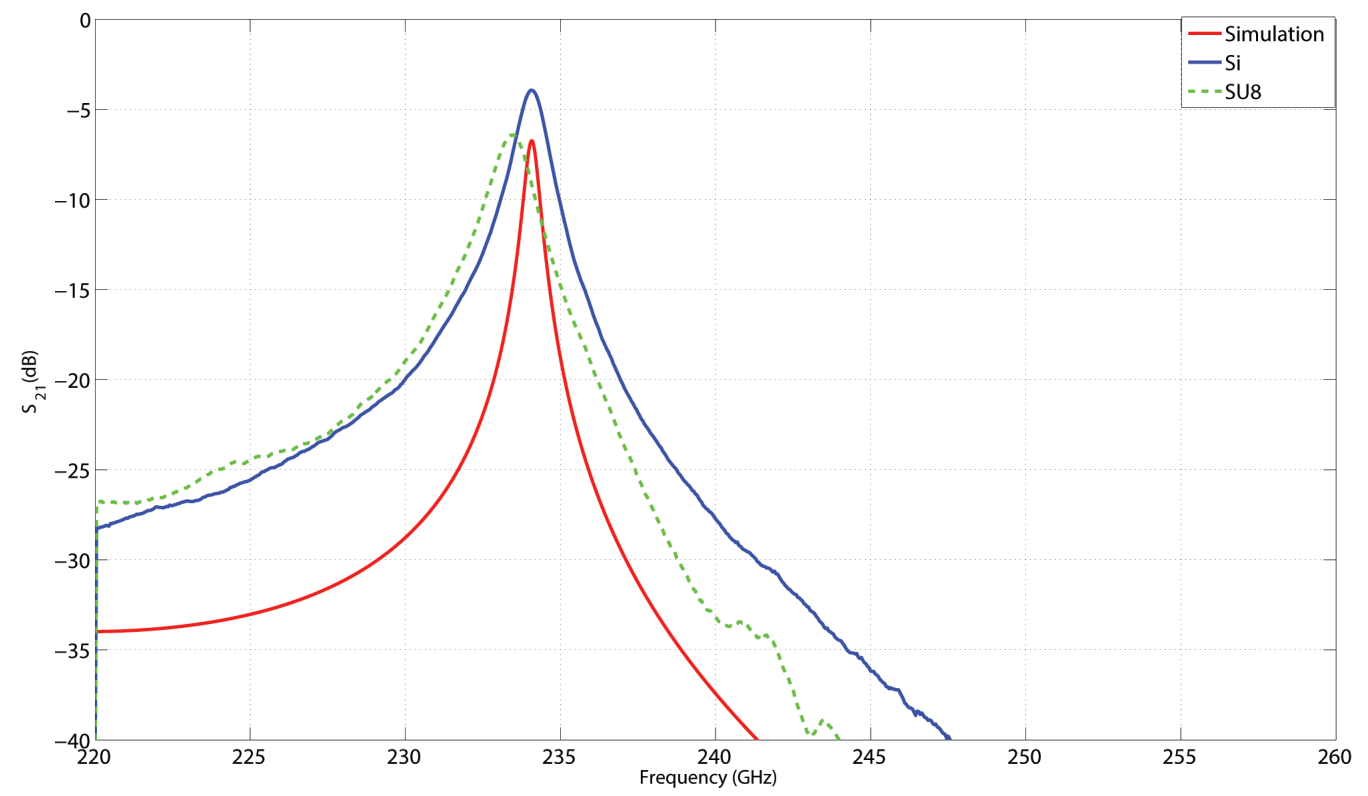

Figure 13: Comparison between the measurements of simulation, Si and SU8 resonators at 220-260 $\mathrm{GHz}$.

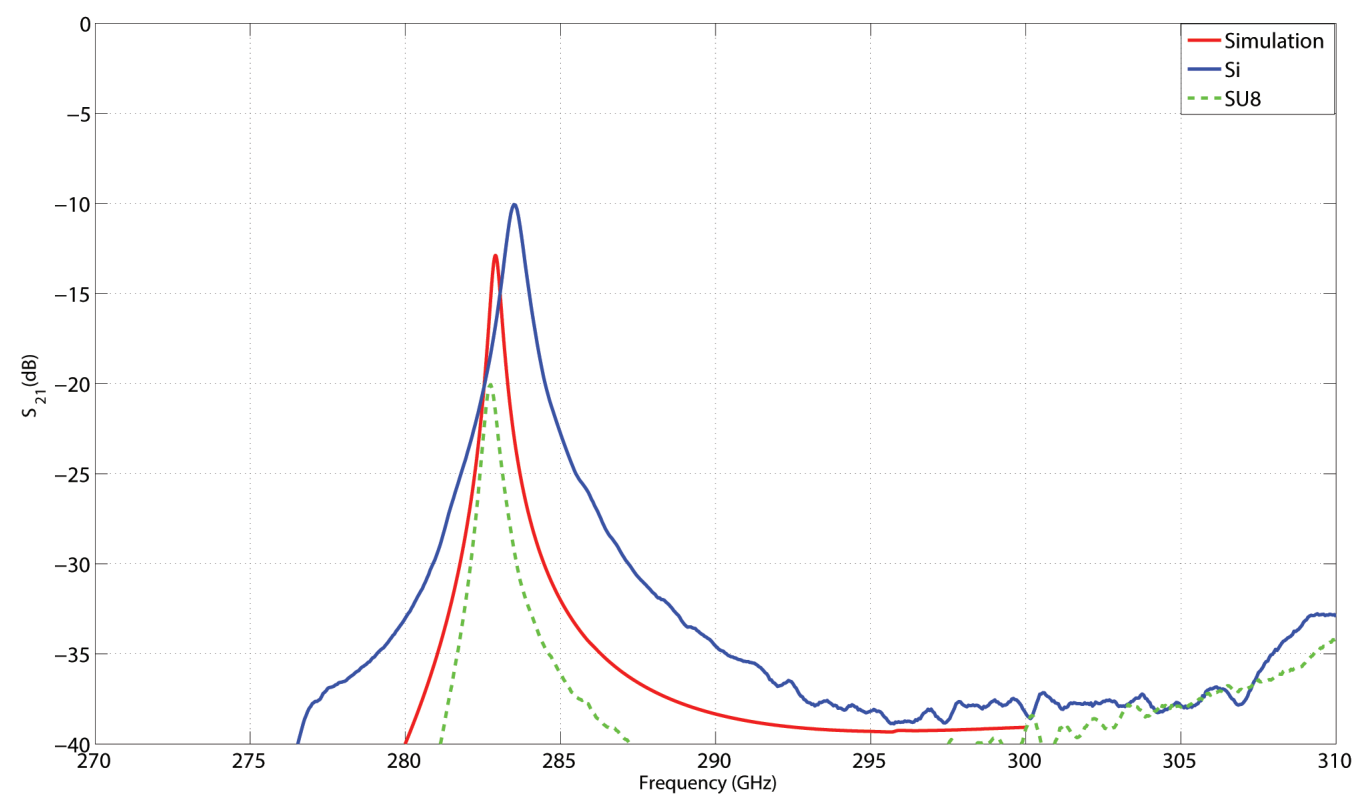

Figure 14: Comparison between the measurements of simulation, Si and SU8 resonators at 270-310 $\mathrm{GHz}$.

$$
\alpha=\beta /\left(2 Q_{u}\right)
$$


The resonance peaks for the SU8-based resonator match those of the Si-based resonator and simulations. The SU8-based resonator shows higher Q-values than the Si-based resonator at higher frequencies. The loss at higher frequencies is comparable to the Si-based resonator.

\section{CONCLUSION}

The first polymer gap waveguide resonator has been presented. The process of creating a two-layer SU8 device with SU8 both as carrier layer and as device layer has been successful. The SU8-based resonator has peaks close to the simulation and the previously presented fabricated Si-based resonator. The unloaded Q-values for the SU8-based resonator are higher for higher frequencies and an attenuation loss of $0.041 \mathrm{~dB} / \mathrm{mm}$ at $282.2 \mathrm{GHz}$ compared to the Si-based resonator with an attenuation loss of $0.043 \mathrm{~dB} / \mathrm{mm}$ at $283.5 \mathrm{GHz}$. The SU8 process has fewer steps compared to the silicon-based process. SU8 is a more flexible material and therefore more robust, with a more cost-effective process.

\section{ACKNOWLEDGEMENTS}

This work has been supported by The Swedish Research Council VR, a project within the VINNOVA-funded Chase antenna systems VINN excellence center at Chalmers, and Chalmers production area of advanced science for funding of the reported work. The authors are grateful to the nanofabrication laboratory at Chalmers University of Technology for their help with the fabrication process.

\section{REFERENCES}

[1] Shang, X.; Ke, M.; Wang, Y.; Lancaster, M. J.: WR-3 and Waveguides and Filters Fabricated Using SU8 Photoresist Micromachining Technology. IEEE Transactions On Terahertz Science And Technology, 2 (2012), 629-637.

[2] Silveirinha, M.G.; Fernandes, C.A.; Costa, J.R.: Electromagnetic Characterization of Textured Surfaces Formed by Metallic Pins. IEEE Transactions on Antennas and Propagation, 56 (2008), 405-415.

[3] Rajo-Iglesias, E.; Kildal, P.-S.: Numerical studies of bandwidth of parallel-plate cut-off realised by a bed of nails, corrugations and mushroom-type electromagnetic bandgap for use in gap waveguides. Microwaves, Antennas \& Propagation, IET, 5 (2011), 282-289.

[4] Kildal, P- S.; Alfonso, E.; Valero-Nogueira, A.; Rajo-Iglesias, E.: Local Metamaterial-Based Waveguides in Gaps Between Parallel Metal Plates. Antennas and Wireless Propagation Letters, IEEE, 8 (2009), 84-87.

[5] Kildal, P.-S.; Zaman, A.U.; Rajo-Iglesias, E.; Alfonso, E.; Valero-Nogueira, A.: Design and experimental verification of ridge gap waveguide in bed of nails for parallel-plate mode suppression. Microwaves, Antennas \& Propagation, IET, 5 (2011), 262-270. 
[6] Zaman, A.U.; Kildal, P- S.; Kishk, A.A.: Narrow-Band Microwave Filter Using High-Q Groove Gap Waveguide Resonators With Manufacturing Flexibility and No Sidewalls. IEEE Transactions on Components, Packaging and Manufacturing Technology, 2 (2012), 1882-1889.

[7] Zaman, A.U.; Alexanderson, M.; Vukusic, T.; Kildal, P.-S.: Gap Waveguide PMC Packaging for Improved Isolation of Circuit Components in High Frequency Microwave Modules. IEEE Transactions on Components, Packaging and Manufacturing Technology, 4(2013), 16-25.

[8] Rahiminejad, S.; Zaman, A.U.; Pucci, E.; Raza, H.; Vassilev, V.; Haasl, S.; Lundgren, P.; Kildal, P.-S.; Enoksson, P.: Micromachined ridge gap waveguide and resonator for millimeterwave applications. Sensors and Actuators A: Physical, 186(2012), 264-269.

[9] Rahiminejad, S.; Pucci, E.; Haasl, S.; Enoksson, P.: Contactless Pin-Flange Adapter for High-Frequency Measurements, 23rd Micromechanics And Microsystems Europe Workshop, Ilmenau, Germany, 2012.

[10] Rahiminejad, S.; Pucci, E.; Haasl, S.; Enoksson, P.: Micromachined Double-Sided SOI PinFlange Adapter for $100 \mathrm{GHz}$, 24th Micromechanics And Microsystems Europe Workshop, Espoo, Finland, 2013.

[11] Rahiminejad, S.; Raza, H.; Zaman, A.U.; Haasl, S.; Enoksson, P.; Kildal, P.-S.: Micromachined gap waveguides for $100 \mathrm{GHz}$ applications, 7th European Conference on Antennas and Propagation (EuCAP), Gothenburg, Sweden, 2013.

[12] Rahiminejad, S.; Algaba Brazlez, A.; Raza, H.; Pucci, E.; Haasl. S.; Kildal, P.-S.; Enoksson, P.:100 GHz SOI gap waveguides, The 17th International Conference on Solid-State Sensors, Actuators and Microsystems , Barcelona, Spain, 2013.

[13] Chollet, F.: Welcome to MEMScyclopedia.org!, 18 Nov. 2013, http://memscyclopedia.org/su8.html

[14] Pucci, E.; Rajo-Iglesias, E.; Kildal, P.-S.: WNew Microstrip Gap Waveguide on MushroomType EBG for Packaging of Microwave Components. Microwave and Wireless Components Letters, IEEE, 22 (2012), 129-131.

[15] Pucci, E.; Zaman, A.U.; Rajo-Iglesias, E.; Kildal, P.-S.; Kishk, A.:Study of Q-factors of ridge and groove gap waveguide resonators.Microwaves, Antennas \& Propagation, IET, 7 (2013), 900-908.

\section{Bibliographies}

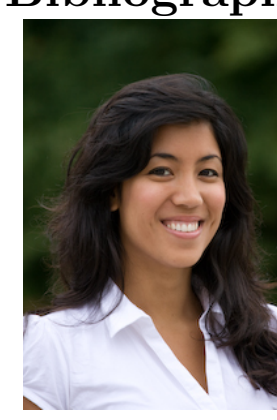
assistant. She received her M.Sc. double diploma from both Katholieke Universiteit Leuven 
and Chalmers University of Technology in Nanoscience and Nanotechnology in 2011 as a part of the Erasmus Mundus master program. She has won two best poster awards at MME in 2012 and 2013. She is currently working towards her Ph.D. in the Micro and Nanosystems group at Chalmers University of Technology, Gothenburg, Sweden. Her interests lie in the field of microand nanosystems.

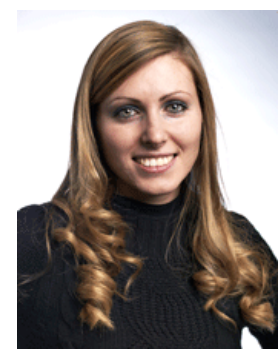

Elena Pucci received the MSc degree in Telecommunication Engineering from University of Siena, Italy, in 2008, and the $\mathrm{PhD}$ degree from Chalmers University of Technology, Sweden, in 2013. Her main research activity includes the development of the new gap waveguide technology for millimeter wave applications, with focus on losses study, packaging capabilities and integration with antennas. Her background covers also the analysis of artificial magnetic conductors and electromagnetic band-gap materials, design of passive microwave components, small antennas and arrays. She received the Second Best Student Paper Award at the European Conference on Antennas and Propagation (EuCAP 2012) in 2012 and the Best Poster Award at Micromechanics and Microsystems Europe Workshop in 2012. She joined Ericsson AB, Sweden, in 2014 .

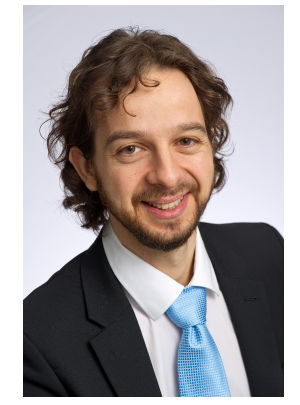

Sjoerd Haasl received the M.Sc. degree with high honors in electrotechnical and mechanical engineering from the University of Leuven, Belgium and the Ph.D. degree in microsystem technology from the Royal Institute of Technology, Stockholm, Sweden. He was a research scientist and business area manager for the inertial sensors business platform at the research institute Imego, Gothenburg, Sweden until 2010. Currently, he works at the Center for Technology in Medicine and Health, a center funded by the Royal Institute of Technology, the Karolinska Institute and the Stockholm City Council. His interests lie in the fields of innovation and microsystems.

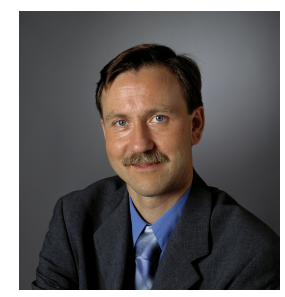

Peter Enoksson received his Ph.D. in 1997 from the Royal Institute of Technology, Stockholm, Sweden. 1997 he became assistant professor and 2000 appointed associate professor at the Royal Institute of Technology, working as project leader in the Microsystem 
Technology group. He was appointed Professor of MOEMS in 2001 at Chalmers University of Technology, Gothenburg, Sweden. 2002 he was appointed vice dean of School of Electrical Engineering and 2003 head of the Solid State Electronics Laboratory. He heads the Micro- and Nanosystems group, department of Microtechnology and Nanoscience and has published more than 200 research journal and conference papers, and has 10 granted patents.

\section{List of figures and tables}

Fig. 1. Illustration of a ridge gap waveguide. The ridge and the lid are PEC surfaces and the pin-surface realizes the AMC surface.

Fig. 2. 2D color plot of the absolute value of E-field for the open circuit ridge gap waveguide resonator.

Fig. 3. Top view of the ridge gap resonator, displaying the dimensions and placements of the pin and the ridge.

Fig. 4. Measurement setup with a photo of the resonator being measured. a) The network analyzer (Agilent N5250C), b) The millimeter-wave controller (Agilent N5260A), c) OML extender, d) WR03 flange, e) Support package for the resonator (Fig. 4).

Fig. 5. A picture of the support package used during measurements with the PEC lid incorporated above and a schematic view of the opening which can fit the ridge gap resonator and have gap of $167 \mu m$ above it.

Fig. 6. Measurement and simulation of the previous Si ridge gap resonator [8].

Fig. 7. a) Si wafer, b) first layer of SU8 dispensed, c) soft-bake, d) flood exposure, e) second layer of SU8, f) second soft-bake, g) patterning, h) developing the SU8, i) $\mathrm{KOH}$ etch of the Si, j) sputtering and electroplating of $\mathrm{Au}$.

Fig. 8. Craters and bubbles appearing after the first soft-bake step, due to unsuccessful dispensing of the SU8.

Fig.9. A complete SU8 wafer.

Fig. 10. SEM image of the a) SU8 ridge gap resonator, with a pin height of $275 \mu \mathrm{m}$ and b) Si-based ridge gap resonator with a pin height of $275 \mu \mathrm{m}$.

Fig. 11. a) SEM image of a SU8 pin on the SU8 carrier. b) SEM image of the Si pins.

Fig. 12. a) Ridge gap resonator made out of only SU8. b) Ridge gap resonator made out of silicon.

Fig. 13. Comparison between the measurements of simulations, Si and SU8 resonator at $220-$ $260 \mathrm{GHz}$.

Fig. 14. Comparison between the measurements of simulations, Si and SU8 resonator at $270-$ $310 \mathrm{GHz}$.

Table 1. Measured unloaded Q-values and loss $/ \mathrm{mm}$. 